CASE REPORT

\title{
Midodrine treatment for chronic fatigue syndrome
}

\author{
J Naschitz, D Dreyfuss, D Yeshurun, I Rosner
}

Postgrad Med J 2004;80:230-232. doi: 10.1136/pgmj.2003.011429

The long term results of midodrine treatment in a patient having debilitating chronic fatigue syndrome (CFS) are reported. Midodrine treatment, directed at the autonomic nervous system, resulted in correction of the dysautonomia followed by improvement of fatigue. This finding is consistent with the hypothesis that dysautonomia plays a major part in the pathophysiology of CFS and that therapies directed at the autonomic nervous system may be effective in the treatment of CFS.

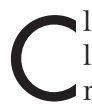

linically evaluated, medically unexplained fatigue of at least six months' duration, that is of new onset, is not a result of ongoing exertion, not substantially alleviated by rest, and substantially reducing previous levels of activity is called chronic fatigue syndrome (CFS). ${ }^{1}$ The diagnosis of CFS is based on patient history and exclusion of other diagnosable medical or psychiatric illnesses. Many therapies have been suggested in CFS but none has been found to be consistently effective. ${ }^{2}$

The pathogenesis of CFS is poorly understood. A close connection between impairment of autonomic functions and CFS has been demonstrated, and can be assessed with the head-up tilt test. ${ }^{3}$ Since dysautonomic cardiovascular reactivity is frequently present in CFS patients, we hypothesised that therapies directed at the autonomic nervous system may also improve fatigue symptoms.

\section{CASE REPORT}

A 26 year old man was referred to the CFS clinic, complaining of fatigue with sudden onset eight months before, associated with headache, unrefreshing sleep, sore throat, enlarged palpable submandibular lymph nodes, diffuse muscle discomfort, and joint pain. The fatigue was substantially reducing his previous levels of occupational, educational, social, and personal activities. Body temperature was normal. The patient was not taking medications or illicit drugs. There were normal findings on physical examination and routine laboratory tests; thyroid stimulating hormone, serological tests for hepatitis B and C, HIV, Epstein-Barr virus and cytomegalovirus, chest radiography, abdominal ultrasound, electrocardiography, and echocardiography were also normal. Psychiatric examination did not reveal a past or current disorder. The diagnosis of CFS was established based on the Centers for Disease Control definition criteria. ${ }^{1}$ The fatigue severity was 22 out of a maximum 33 points according to the modified Chalder fatigue severity scale. ${ }^{4}$ A standard head-up tilt test showed normal cardiovascular reactivity by classical criteria; however, the calculated haemodynamic instability score (HIS) +2.2 was pathological (fig 1). Prior studies showed that patients with CFS usually exhibit a HIS greater than $-0.98 .^{56}$ The patient agreed to enter a therapeutic trial with midodrine $\mathrm{HCl}$, a potent $\left(\alpha-1\right.$-adrenergic agonist). ${ }^{7}$ Oral midodrine treatment was started, $2.5 \mathrm{mg}$ twice daily. At two week intervals, fatigue severity questionnaires were administered and the head-up tilt test repeated. The dose of midodrine was increased until his HIS was less than -0.98 . Subsequent visits were scheduled at two month intervals. The patient's course is illustrated in fig 2. After three months of treatment (visit 6 in fig 2), while taking 7.5 mg midodrine daily, the HIS was -1.98 (within normal range). Significant remission of fatigue occurred a few weeks later and the patient returned to regular activities. Two months later the patient underwent surgery for perforated duodenal ulcer. Midodrine treatment was discontinued. Recovery from surgery was uneventful, however, fatigue became disturbing and HIS +8.29 was noted (visit 8 in fig 2 ). Ten mg midodrine daily was prescribed, and was followed by normalisation of the HIS and remission of fatigue. At this time, the patient's activities included jogging for $10 \mathrm{~km}$. Three months later, in an attempt to taper midodrine, the HIS increased, while the patient was free of symptoms. The previous $10 \mathrm{mg}$ dose was resumed. One year later another attempt to taper midodrine was associated with recurrence of fatigue and abnormal HIS (visit 14 in fig 2). Currently, the patient is taking $10 \mathrm{mg}$ midodrine daily and is free of symptoms.

\section{DISCUSSION}

The observations regarding this patient may shed light on three issues: the role of dysautonomia in the pathogenesis of CFS, the role of autonomic testing in the diagnosis of CFS, and the possibility of treating CFS by drugs that act on the autonomic nervous system.

In CFS, abnormalities of central nervous activity have been demonstrated on magnetic resonance imaging and single photon emission tomography, ${ }^{8}$ disruption of the hypothalamic-pituitary-adrenal axis and serotoninergic and noradrenergic pathways have been demonstrated, and a "distal dysautonomia" has been described. ${ }^{9}$ Blood pressure and heart rate measurements during orthostatic challenge can be used as one measure of cardiovascular autonomic activity as the fast response of blood pressure and heart rate to acute stimuli is under autonomic nervous control. For this purpose, the head-up tilt test is used. Classical pathological reactions to the head-up tilt test are: vasodepressor reaction, cardioinhibitory reaction, orthostatic hypotension, and postural tachycardia syndrome. ${ }^{39}$ In studies utilising these outcome measures, evidence for abnormal cardiovascular reactivity was found in one half of CFS patients. ${ }^{359}$ The latter measures are non-specific, however, also occurring in a variety of disorders unrelated to CFS. A method, recently proposed for the study of the cardiovascular reactivity of CFS patients involves computing changes in blood pressure and heart rate during the course of a head-up tilt test, followed by processing the data by image analysis methods. These data receive numerical expression as the HIS. ${ }^{5}$ According to results of our previous study, the best cut off differentiating CFS from healthy is HIS -0.98 . HIS values greater than -0.98 are usually associated with CFS (sensitivity 90.3\% and

Abbreviations: CFS, chronic fatigue syndrome; HIS, haemodynamic instability score 
A

\begin{tabular}{|c|c|c|c|c|c|}
\hline Systolic & Diastolic & Heart rate & SYS-DIF-c & SYS-DIF-a & HR-DIF-c \\
\hline 120 & 78 & 70 & 0.020 & 0.020 & 0.045 \\
\hline 120 & 76 & 71 & 0.020 & 0.020 & 0.060 \\
\hline 120 & 74 & 67 & 0.020 & 0.020 & 0.000 \\
\hline 110 & 80 & 84 & -0.083 & 0.083 & 0.254 \\
\hline 100 & 70 & 82 & -0.167 & 0.167 & 0.224 \\
\hline 104 & 76 & 85 & -0.133 & 0.133 & 0.269 \\
\hline 106 & 70 & 84 & -0.117 & 0.117 & 0.254 \\
\hline 108 & 70 & 86 & -0.100 & 0.100 & 0.284 \\
\hline 110 & 76 & 87 & -0.083 & 0.083 & 0.299 \\
\hline 108 & 76 & 85 & -0.100 & 0.100 & 0.269 \\
\hline 104 & 80 & 83 & -0.133 & 0.133 & 0.239 \\
\hline 110 & 88 & 100 & -0.083 & 0.083 & 0.493 \\
\hline 112 & 84 & 97 & -0.067 & 0.067 & 0.448 \\
\hline
\end{tabular}

B

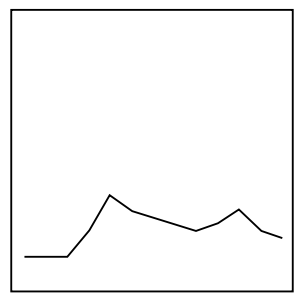

C

\begin{tabular}{|l|r|}
\hline SYS-DIF-c-SD & 0.062 \\
\hline HR-DIF-c-SD & 0.142 \\
\hline SYS-DIF-a-FD & 1.144 \\
\hline HIS & 1.951 \\
\hline
\end{tabular}

Figure 1 Processing the HIS. Systolic and diastolic blood pressure (BP) and heart rate (HR) values of a patients with CFS, taken with a sphygmomanometer throughout the head-up tilt test are represented in (A). From the measured values, the relative changes of $B P$ and $H R$ were calculated, according to the equation: $\mathrm{BP}$ difference $=\mathrm{BP}$ (n1....n13) - BPn3/BPn3. Absolute values were then obtained by converting all results to positive numbers. Shown in the table are systolic BP differences as current (c) and absolute (a) values, as well as HR differences in current values (c). The BP and $H R$ changes used to calculate the SYS-DIF-c-SD and HR-DIF-c-SD (C), which are independent predictors of the HIS. The third independent predictor of HIS is the SYS-DIF-a-FD, and is processed from the time curve of the systolic BP differences (B) by a fractal analysis program. Finally, the three independent predictors are applied to compute the HIS (C). In this specific case, HIS +1.95 is typical for CFS. specificity $84.5 \%$ ). The reproducibility of the HIS was validated with reference to the -0.98 cut off. ${ }^{6}$

Many therapies have been suggested in CFS: amantadine, doxycycline, acyclovir, immune serum globulin, dialysable leucocyte extract, interferons, fluorocortisone, cimetidine, ranitidine, magnesium, primrose oil, vitamin B12, Ampligen, essential fatty acids, liver extract, exclusive diets, and removal of dental fillings. A systematic review of 350 studies revealed that only cognitive behaviour therapy and graded exercise are consistently beneficial. ${ }^{2}$ A pilot study of midodrine treatment in CFS showed encouraging results; however, these results are preliminary. ${ }^{10}$ In the patient reported here, midodrine treatment resulted first in correction of dysautonomia as monitored by HIS on tilt test, followed by improvement of fatigue. Suspending midodrine treatment or decreasing the dose was associated with recurrence of dysautonomia and fatigue. These observations may spur larger prospective studies on the principle of manipulating

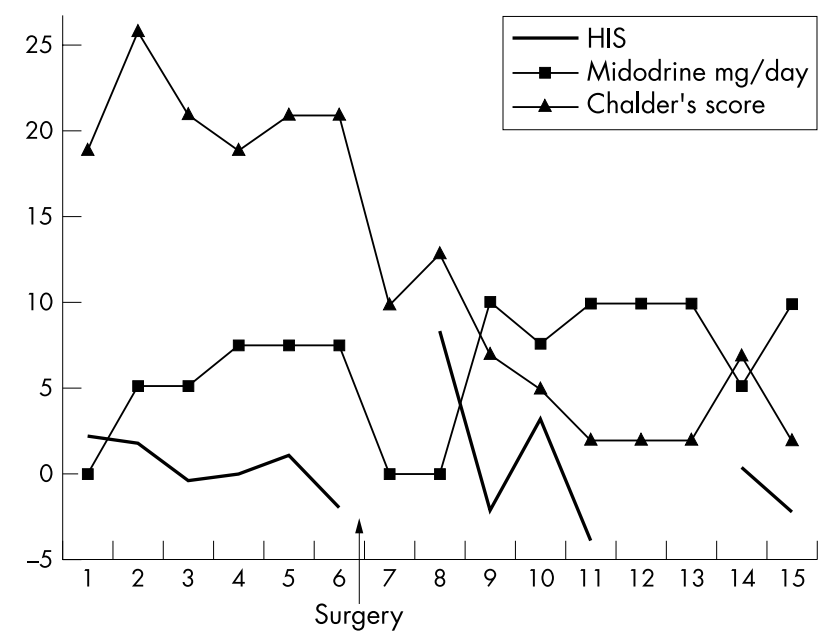

Figure 2 Longitudinal study of fatigue scores and HIS over 15 visits. the autonomic nervous system to improve both dysautonomic phenomena and fatigue in CFS. Perforation of duodenal ulcer occurred while our patient was taking midodrine and no other medication, but midodrine was tolerated later. We did not find any reports in the literature of exacerbation of peptic disease during the course of midodrine treatment.

There is need for a placebo controlled trial before midodrine is considered to be a treatment for CFS.

\section{Authors' affiliations}

J Naschitz, D Dreyfuss, D Yeshurun, Department of Internal Medicine A, Bnai Zion Medical Center and Bruce Rappaport Faculty of Medicine, Technion-Israel Institute of Technology, Haifa, Israel

I Rosner, Department of Rheumatology, Bnai Zion Medical Center and Bruce Rappaport Faculty of Medicine, Technion-Israel Institute of Technology, Haifa, Israel

Correspondence to: Dr Jochanan E Naschitz, Department of Internal Medicine A, Bnai Zion Medical Center, Haifa 31048, PO Box 4940, Israel; Naschitz@tx.technion.ac.il

\section{Learning points}

- The diagnosis of CFS is based on patient history and exclusion of other medical or psychiatric illnesses.

- A particular dysautonomia was revealed in CFS patients on head-up tilt test. The dysautonomic fingerprint of CFS, expressed as "HIS", may provide objective criteria to the diagnosis.

- Review of 350 studies on treatment of CFS showed that only cognitive behaviour therapy and graded exercise were consistently beneficial.

- A pilot study of midodrine treatment in CFS showed promising outcomes, resulting in correction of the dysautonomia followed by improvement of fatigue. 
Submitted 19 June 2003

Accepted 15 September 2003

\section{REFERENCES}

1 Fukuda K, Straus SE, Hickie I, et al. The chronic fatigue syndrome: a comprehensive approach to its definition and study. International Study Group. Ann Intern Med 1994;121:953-9.

2 Whiting $\mathbf{P}$, Bagnall A, Sowden A, et al. Interventions for the treatment and management of the chronic fatigue syndrome. JAMA 2001;286:1360-8.

3 Bou-Holaigah I, Rowe PC, Kan J, et al. The relationship between neurally mediated hypotension and the chronic fatigue syndrome. JAMA 1995;274:961-7.

4 Chalder T, Berelowitz G, Pawlikowska T, et al. Development of a fatigue scale. J Psychosom Res 1993;37:147-53.
5 Naschitz JE, Sabo E, Naschitz S, et al. Hemodynamic instability in chronic fatigue syndrome: indices and diagnostic significance. Semin Arthritis Rheum 2001;31:199-208.

6 Naschitz JE, Rosner I, Rozenbaum M, et al. The head-up tilt test with hemodynamic instability score in diagnosing chronic fatigue syndrome. Q J Med 2003;96:133-42.

7 Klingenheben T, Credner S, Hohnloser SH. Prospective evaluation of a twostep therapeutic strategy in neurocardiogenic syncope: midodrine as second line treatment in patients refractory to beta-blockers. Pacing Clin Electrophysiol 1999:22:276-81

8 Costa DC, Tannock C, Brostoff J. Brainstem perfusion is impaired in chronic fatigue syndrome. Q J Med 1995;88:767-73.

9 Streeten DH, Anderson GH Jr. The role of delayed orthostatic hypotension in the pathogenesis of chronic fatigue. Clin Auton Res 1998;8:119-24.

10 Naschitz JE, Rosner I, Rozenbaum M, et al. Successful treatment of chronic fatigue syndrome with midodrine: a pilot study. Clin Exp Rheumatol 2003;21:146-7.

\section{Clinical Evidence-Call for contributors}

Clinical Evidence is a regularly updated evidence based journal available worldwide both as a paper version and on the internet. Clinical Evidence needs to recruit a number of new contributors. Contributors are health care professionals or epidemiologists with experience in evidence based medicine and the ability to write in a concise and structured way.

\section{Currently, we are interested in finding contributors with an interest in} the following clinical areas:

Altitude sickness; Autism; Basal cell carcinoma; Breast feeding; Carbon monoxide poisoning; Cervical cancer; Cystic fibrosis; Ectopic pregnancy; Grief/bereavement; Halitosis; Hodgkins disease; Infectious mononucleosis (glandular fever); Kidney stones; Malignant melanoma (metastatic); Mesothelioma; Myeloma; Ovarian cyst; Pancreatitis (acute); Pancreatitis (chronic); Polymyalgia rheumatica; Post-partum haemorrhage; Pulmonary embolism; Recurrent miscarriage; Repetitive strain injury; Scoliosis; Seasonal affective disorder; Squint; Systemic lupus erythematosus; Testicular cancer; Varicocele; Viral meningitis; Vitiligo However, we are always looking for others, so do not let this list discourage you.

Being a contributor involves:

- Appraising the results of literature searches (performed by our Information Specialists) to identify high quality evidence for inclusion in the journal.

- Writing to a highly structured template (about 2000-3000 words), using evidence from selected studies, within 6-8 weeks of receiving the literature search results.

- Working with Clinical Evidence Editors to ensure that the text meets rigorous epidemiological and style standards.

- Updating the text every eight months to incorporate new evidence.

- Expanding the topic to include new questions once every 12-18 months.

If you would like to become a contributor for Clinical Evidence or require more information about what this involves please send your contact details and a copy of your CV, clearly stating the clinical area you are interested in, to Claire Folkes (cfolkes@bmigroup.com).

\section{Call for peer reviewers}

Clinical Evidence also needs to recruit a number of new peer reviewers specifically with an interest in the clinical areas stated above, and also others related to general practice. Peer reviewers are health care professionals or epidemiologists with experience in evidence based medicine. As a peer reviewer you would be asked for your views on the clinical relevance, validity, and accessibility of specific topics within the journal, and their usefulness to the intended audience (international generalists and health care professionals, possibly with limited statistical knowledge). Topics are usually 2000-3000 words in length and we would ask you to review between 2-5 topics per year. The peer review process takes place throughout the year, and our turnaround time for each review is ideally 10-14 days.

If you are interested in becoming a peer reviewer for Clinical Evidence, please complete the peer review questionnaire at www.clinicalevidence.com or contact Claire Folkes(cfolkes@bmigroup.com). 